\title{
Renal manifestations of rheumatic diseases. A review
}

\author{
Pavel Horak ${ }^{a}$, Andrea Smrzova ${ }^{a}$, Karel Krejcia, Tomas Tichy ${ }^{b}$, Josef Zadrazila, Martina Skacelovaa ${ }^{a}$
}

\begin{abstract}
Background. Renal manifestations of rheumatic diaseases are sometimes very discrete and mild. At others, they can present the leading symptomatology of a given disease.

Systemic lupus erythematosus, systemic scleroderma, renal vasculitis, rheumatoid arthritis, mixed connective tissue disease, Sjögren's syndrome and gout can all manifest in or be accompanied by renal impairment.

Methods and Results. The authors reviewed the literature on renal manifestation of rheumatic diseases using the key words, lupus erythematosus, systemic autoimmune diseases, rheumatoid arthritis, vasculitis and gout. The review below is accompanied by their own histological findings.

Conclusion. Diagnosis requires proper interpretation of the clinical situation, laboratory results and image analysis methods plus close interdisciplinary collaboration between nephrologist and clinical pathologist/nephropathologist.
\end{abstract}

Key words: kidney, rheumatic diseases, systemic autoimmune diseases, rheumatoid arthritis, vasculitis, gout, drugs

Received: January 24, 2013; Accepted: May 23, 2013; Available online: June 7, 2013

http://dx.doi.org/10.5507/bp.2013.042

${ }^{a}$ Department of Internal Medicine III - Nephrology, Rheumatology and Endocrinology, Faculty of Medicine and Dentistry, Palacky University Olomouc, Czech Republic

${ }^{b}$ Department of Clinical and Molecular Pathology, Faculty of Medicine and Dentistry, Palacky University Olomouc

Corresponding author: Pavel Horak, e-mail: Pavel.Horak@fnol.cz

\section{INTRODUCTION}

A number of rheumatic diseases can manifest in the kidneys and urinary tract. The manifestations are sometimes very discrete and mild. At others, they can present leading symptomatology of a given disease. For example, renal impairment is one of the most significant manifestations of Systemic Lupus Erythematosus (SLE). It determines fundamentally the prognosis of systemic scleroderma, is an inseparable part of the clinical picture of renal vasculitis, can accompany rheumatoid arthritis, mixed connective tissue disease, Sjögren's syndrome or hyperuricemia and gout. Determination of diagnosis requires proper interpretation of the clinical situation, laboratory results and image analysis methods, and close interdisciplinary collaboration between nephrologist and clinical pathologist/nephropathologist $\mathrm{t}^{1,2}$.

\section{SYSTEMIC LUPUS ERYTHEMATOSUS (SLE) AND ANTIPHOSPHOLIPID SYNDROME}

Renal impairment in SLE is a significant factor of poor prognosis. Until recently, lupus nephritis was the main cause of death as a result of the disease and it is still the main factor in significant morbidity in $30 \%$ of patients $^{3}$. A certain degree of renal impairment is present in almost all patients who have undergone kidney biopsy. In SLE, the presence of glomerulonephritis is the main pathogenetic factor of renal impairment. The histologic classification of WHO and its revision from 2004 distinguishes 6 major classes of glomerulonephritis and the classification is currently completed with indices of activity and chronicity ${ }^{4}$. In SLE there is also need to take into consideration autoimmune interstitial nephritis and vascular, mainly microangiopatic renal impairment in relation to antiphospholipid syndrome or Thrombotic Thrombocytopenic Purpura/ Hemolytic Uremic Syndrome (TTP/HUS) (ref. ${ }^{5}$ ). Lupus nephritis occurs particularly frequently in cases manifesting at younger age; differences in incidence rates between men and women are not significant. The manifestation of renal disease is often non-characteristic, the urinalysis is negative or non-characteristic in a number of mesangial and even membranous nephritis. Lupus nephritis is characteristically manifested by proteinuria and its consequences including manifestation of nephrotic syndrome which does not clinically differ from nephrotic syndrome of other causes. The tendency towards accelerated atherosclerosis and higher incidence of renal vein thrombosis mainly stand out from complications of the nephrotic syndrome in SLE. Although microscopic hematuria is common, macroscopic hematuria is rare and occurs almost exclusively in children ${ }^{6}$. Active urine sediment with the presence of mainly granular casts (cylinders) is common and occurs in 1/3 of patients ${ }^{7}$. Renal impairment is also frequently manifested through hypertension which occurs in $55 \%$ of patients with lupus nephritis of class IV $\left(\right.$ ref. $\left.^{8}\right)$. A substantial part of patients may show different degree of renal insufficiency which may develop from damage to the glomeruli. Acute renal insufficiency is often developed in relation to capillary microthrombi in TTP/HUS or thrombosis of renal arteries and veins as significant complications of SLE and the antiphospholipid syndrome. Acute interstitial nephritis connected with immune complexes along tubular basement membrane and 

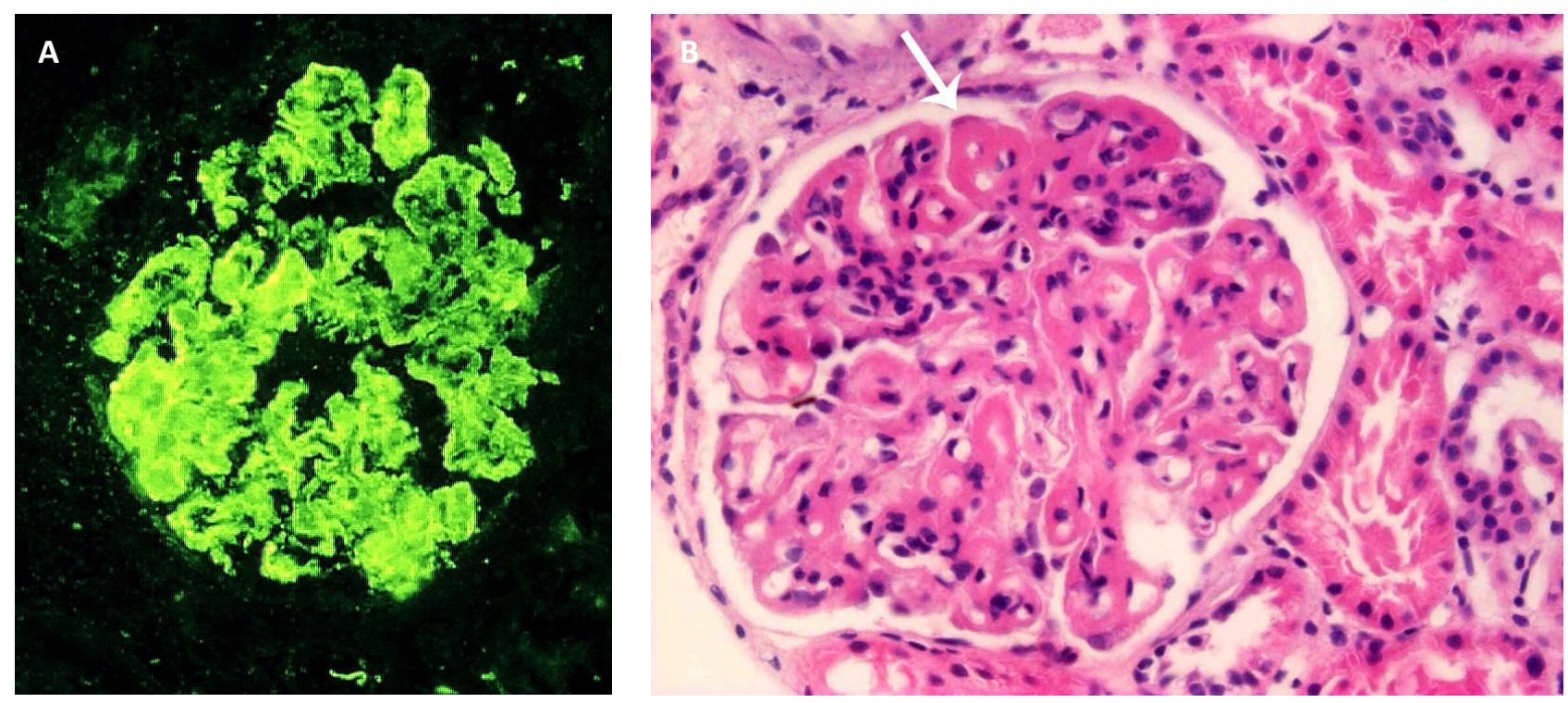

Fig. 1. Lupus nephritis class IV. Immunofluorescence examination on the left shows intensive mesangial positivity and capillary positivity of immune complexes containing IgG,IgA,IgM,C3, C4,C1q (full house) (A). Diffuse proliferative glomerulonephritis, right arrow points to the” wire loop“. H\&E staining, magnification x200 (B).

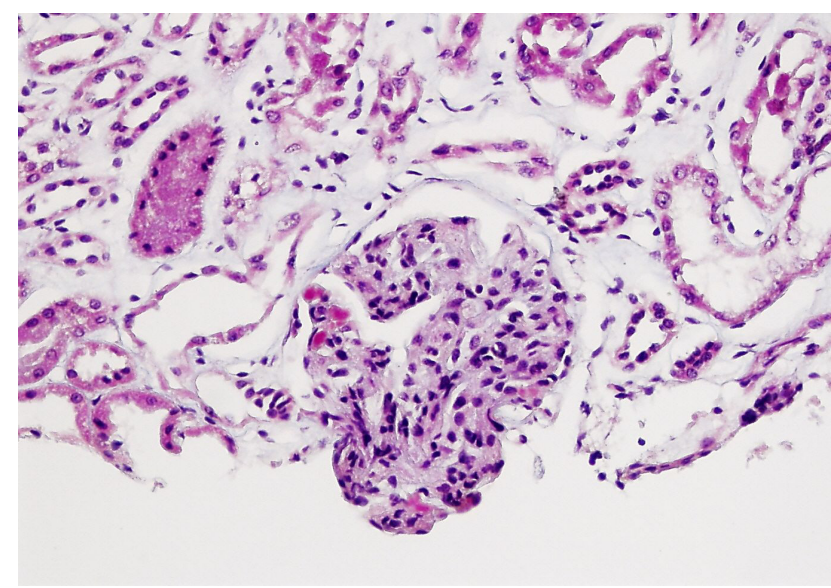

Fig. 2. Thrombotic microangiopathy in TTP/HUS in SLE. Fibrin thrombi in the capillary loops highlighted by special stain, thrombi stained red (arrow). In the hematoxylin and eosin staining, fibrin thrombi in capillaries or arterioles may not be visible. Blue Trichrome Stain, magnification x200.

non-correlating with the presence and activity of glomerulonephritis may also occur within SLE. Both proximal and distal tubular syndromes are present in many patients with SLE; they are often associated with manifestations of secondary Sjögren's syndrome and positivity of anti-Ro and/ or anti-La antibodies. The diagnosis of renal impairment is based on detailed clinical and laboratory examination completed with histological examination of a sample from renal biopsy (Fig. 1, 2).

\section{SYSTEMIC SCLERODERMA}

In systemic scleroderma, autopsies reveal renal impairment in $60-80 \%$ of patients ${ }^{8}$. The clinical symptoms of renal impairment such as mild proteinuria, hypertension or mildly elevated serum creatinine concentration are usually connected with favorable prognosis without any tendency to progression of the renal impairment. Scleroderma renal crisis is the most severe type of renal impairment in scleroderma.

Renal crisis affects $10-20 \%$ of patients with the diffuse form of scleroderma, in the majority of cases within the first five years of the onset of the disease ${ }^{9}$. Renal crisis is thrombotic microangiopathy affecting the kidneys, similar to TTP/HUS, malignant hypertension or antiphospholipid syndrome. Histologic correlate is presented by specific proliferation in the intima of arcuate and renal interlobular arteries and arterioles leading to narrowing or even obliteration of arteries with the formation of typical concentric hypertrophy ("onion skin") (ref. $\left.{ }^{10}\right)$. Proliferative changes can be accompanied by arterial thrombosis and necrosis. Necrosis of the glomeruli is less frequent. The prognosis of this condition is very serious; prior to the introduction of angiotensin-converting enzyme (ACE) inhibitors, almost all patients with significant renal insufficiency died within one year ${ }^{11}$. Major clinical findings in renal crisis are acute renal insufficiency - in the majority of cases - without previous symptoms of significant renal disease, sudden elevation of blood pressure, and frequently accompanied by signs of malignant hypertension as hypertension encephalopathy, retinopathy, left ventricular failure and only unobtrusive changes in urine sediment (mild proteinuria and/or hematuria). Renal crisis occurs more often in patients with diffuse, rapidly progressing scleroderma ${ }^{12}$. Administration of large amounts of glucocorticoids, cyclosporine A use or the presence 


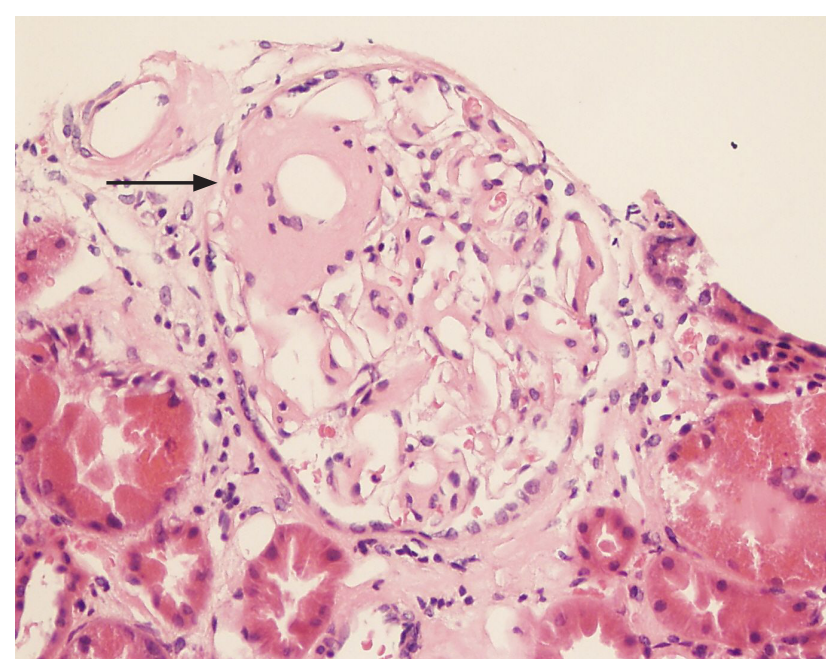

Fig. 3. AA amyloidosis in patient with rheumatoid arthritis. Glomerulus and arteriole (arrow) with amorphous light-redcolored deposits of amyloid. The appearance of the amyloid or its position do not enable determination of the type; the type can be determined immunohistochemically. H\&E staining, magnification $\mathrm{x} 200$.

of anti-RNA polymerase antibodies also present risk factors ${ }^{13}$. Blood pressure has to be monitored regularly in all patients with systemic scleroderma.

\section{MIXED CONNECTIVE TISSUE DISEASE}

As a syndrome combining manifestations of systemic lupus, systemic sclerosis and myositis this is immunologically characterized by high titers of anti-RNP antibodies. Membranous glomerulopathy or mesangial proliferative glomerulonephritis are the main renal manifestations ${ }^{14}$. Other renal manifestations such as diffuse proliferative glomerulonephritis, vascular or glomerular sclerosis are less common. It is clinically manifested mainly with proteinuria, rarely with hematuria. Nephrotic syndrome and chronic renal insufficiency may develop. Scleroderma renal crises accompanied by malignant hypertension may occur rarely ${ }^{12}$.

\section{POLYMYOSITIS (PM) AND DERMATOMYOSITIS (DM)}

Although acute renal failure in mechanical or metabolic rhabdomyolysis is very common, in idiopathic myositis it occurs only very rarely. Cases of mesangial proliferative glomerulonephritis are in idiopathic myositis described only in individual cases ${ }^{12,15}$.

\section{SJÖGREN'S SYNDROME}

Renal impairment is not clinically diagnosed very often; nevertheless, frequent subclinical forms can be as-

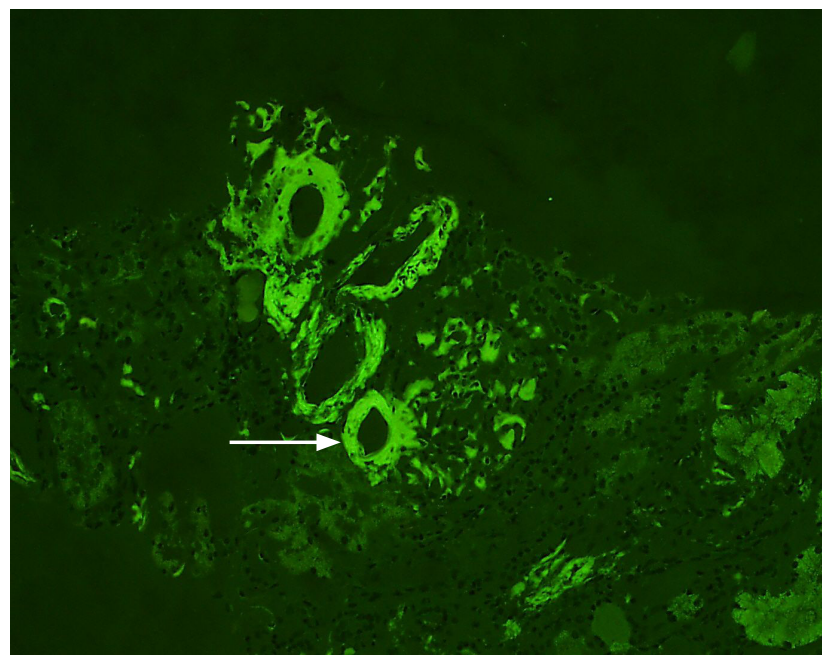

Fig. 4. AA amyloidosis in patient with rheumatoid arthritis. Immunofluorescence examination of amyloid after thioflavin staining confirms the presence of amyloid. The type of amyloid can be determined immunohistochemically with the use of relevant antibodies against light chains, SAA protein, transthyretin, and other. The arrow points to afferent arteriole and its adjacent glomerulus. Magnification x100.

sumed. Although it is usually mild, it can result inacute or chronic renal insufficiency. Tubulointerstitial nephritis which has a histologically chronic character with focal lymphoplasmacytic infiltrate and a majority of $\mathrm{T}$ lymphocytes, is the most common clinical manifestation. Glomerular damage is rare. Whereas urinalysis results are usually very mild and non-characteristic, with only slight proteinuria or leukocyturia, quite common is the incidence of tubular functional disturbances and syndromes such as, renal tubular acidosis, glycosuria despite normal blood glucose level, nephrogenic diabetes insipidus, Fanconi's syndrome (renal tubular acidosis, glycosuria, aminoaciduria) and disorders of renal concentrating ability $^{16,17}$.

\section{RHEUMATOID ARTHRITIS (RA)}

Secondary amyloidosis and drug-induced renal impairment, rarely glomerulonephritis, are the main reasons for renal impairment in RA. In developed countries, RA is the most common cause of the development of secondary (AA) amyloidosis ${ }^{18}$, even though its incidence has dramatically decreased in the last 20 years ${ }^{19}$. The reason for this decrease is probably higher level of awareness about the risk connected with permanent increase in acute-phase reactants, including CRP, and the availability of highly effective and more aggressive treatment of the disease. Secondary amyloidosis can also occur in severe forms of seronegative spondylarthritis. Glomerulonephritis within RA is quite rare; the presence of mesangial proliferative, membranous glomerulonephritis or even crescentic glomerulonephritis was described in more extensive bioptic and autopsy studies, but with little clinical significance. It is manifested clinically with proteinuria and isolated 


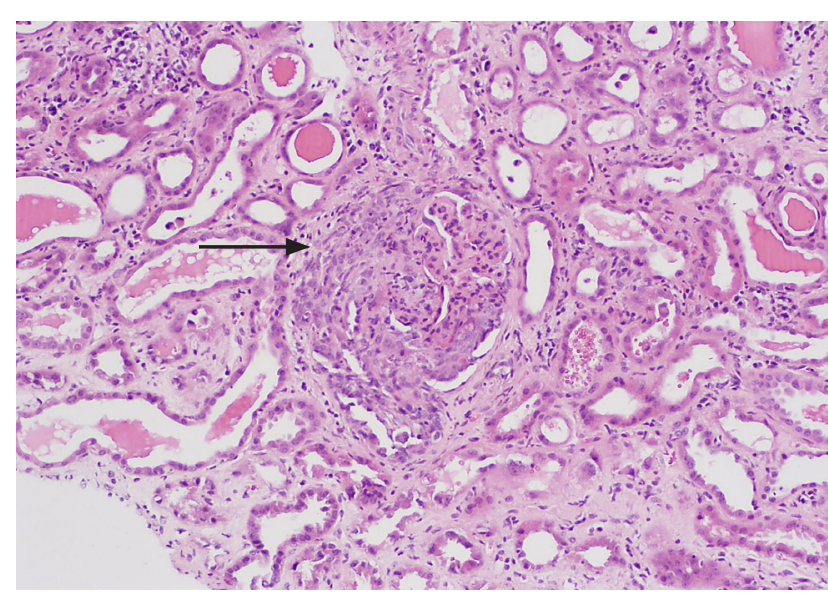

Fig. 5. Wegener's granulomatosis. The center of the image shows glomerulus with necrosis affecting more than $50 \%$ of capillary tuft with voluminous cellular crescent (arrow). Surrounding tubules with flattened epithelium and signs of ischemia, i.e. with acute tubular necrosis. H\&E staining, magnification $\mathrm{x} 200$.

microscopic hematuria. IgA nephropathy has rarely been described. Renal necrotizing vasculitis with microscopic hematuria, proteinuria and renal insufficiency occurs rarely in patients with severe forms of seropositive and erosive rheumatoid arthritis (RA) $\left(\right.$ ref. $^{20}$ ) (Fig. 3, 4).

\section{SERONEGATIVE SPONDYLARTHRITIS (ANKYLOSING SPONDYLITIS, PSORIATIC ARTHRITIS)}

Even if the renal damage directly associated with seronegative spondylarthritis is very rare, there are reports on the $\operatorname{IgA}$ nephropathy related to these disorders ${ }^{21}$. Secondary amyloidosis is occasionally reported as a complication of severe forms of ankylosing spondylitis ${ }^{22}$, the subclinical forms might be detected in up to $7 \%$ of ankylosing spondylitis patients with disease duration longer than 5 years $^{23}$.

\section{VASCULITIDES}

They include a very heterogeneous group of diseases with unifying disease feature of inflammation of an arterial wall. Renal impairment forms the part of clinical picture in many of these diseases ${ }^{24}$.

Polyarteritis nodosa is one of the first described vasculitis. It is commonly associated with hypertension ${ }^{25}$. Its occurrence is quite rare and it affects small and medium-sized arteries. In the majority of cases it occurs as consequence of hepatitis B infection. Antineutrophil cytoplasmic antibodies (ANCA) are present in less than $5 \%$ of $\operatorname{cases}^{26}$. Renal impairment is probably associated with ischemic nephropathy, which can be accompanied by malignant hypertension. Renal insufficiency is the outcome of renal impairment. Angiography can prove the

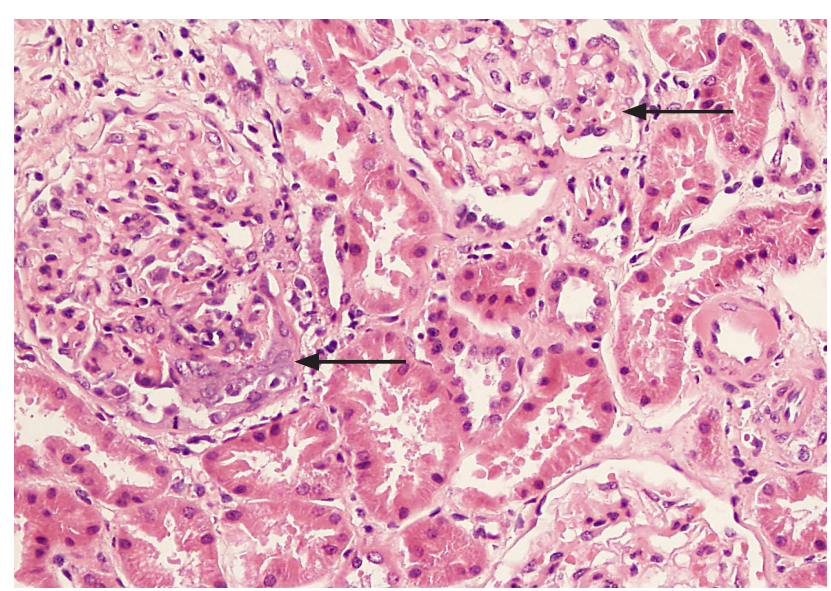

Fig. 6. Henoch-Schonlein purpura. The left side of the picture demonstrates glomerulus with segmental necrosis and small cellular crescent (arrow). The right side of the picture shows two glomeruli; one of them apparently shows focus of early endocapillary proliferation (arrow); right bottom edge shows glomerulus of adequate appearance. H\&E staining, Magnification x200.

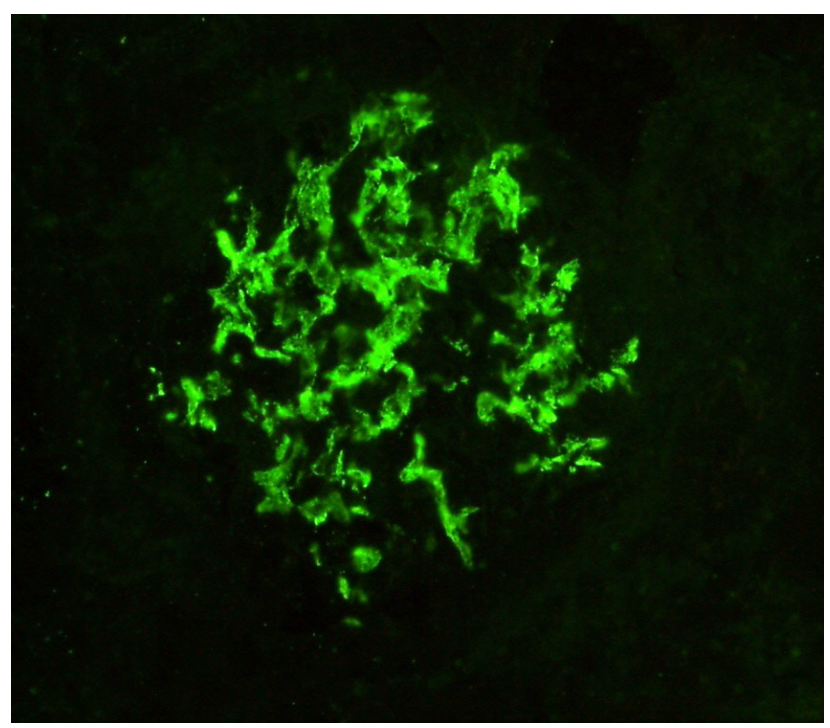

Fig. 7. Henoch-Schonlein purpura. Typical granular mesangial IgA positivity in the glomerulus. Magnification x200.

presence of multiple stenoses and microaneurysms of visceral or renal arteries. Renal infarctions and parenchymal scarring due to arterial stenosis are the reasons for the renal insufficiency. Ruptures of aneurysms are rare, but they can complicate renal biopsy ${ }^{27}$.

Antineutrophil cytoplasmic antibodies (ANCA)associated renal vasculitis are characterized histologically by necrotizing inflammation of small-sized arteries, arterioles, capillaries and venules, chronic sclerosing changes, and in some cases by granuloma formation ${ }^{28}$. They are clinically manifested by purpura, mononeuritis multiplex, pulmonary hemorrhage, visceral infarctions, necrotic changes in mucosa, mostly in the upper respiratory tract, opthalmopathy or otitis. Renal impairment is caused by pauci-immune necrotizing glomerulonephritis with crescent formation which can be also manifested as 
rapidly progressive glomerulonephritis (RPGN) $\left(\right.$ ref. $\left.^{29}\right)$. Pauci-immune glomerulonephritis is unlike lupus nephritis characterized by the absence of significant deposits of immunoglobulins or complement deposition. ANCA antibodies are associated with many cases of granulomatosis with polyangiitis (Wegener's), the Churg-Strauss syndrome or microscopis polyangitis.

- Granulomatosis with polyangiitis (Wegener's granulomatosis) $\left(\right.$ ref. $^{30}$ ) which is a serious form of cANCA associated vasculitis with involvement of the upper respiratory tract, trachea, lungs and kidneys, characteristically connected with necrotizing granulomatous inflammation (Fig. 5).

- Churg-Strauss syndrome characterized by vasculitis, granuloma formation and significant eosinophilia and the presence of allergy or asthma and pulmonary infiltrates ${ }^{31}$.

- Microscopic polyangiitis is non-granulomatous vasculitis which is often histologically indistinguishable from both above mentioned types. Diagnosis is determined by the absence of typical clinical features of granulomatosis with polyangiitis or Churg-Strauss syndrome. Microscopic polyangiitis may gradually develop into both diseases ${ }^{32}$.

\section{Henoch-Schonlein purpura}

This is a relatively common vasculitis of small-sized vessels manifesting as multiple organ involvement including the skin, gastrointestinal tract, kidneys and joints. It is ANCA negative leucocytoclastic vasculitis. Renal impairment is variable. Whereas pediatric sources describe renal impairment as only temporary and mild; nephrological sequelae frequently describe severe and progressive form of disease in adults as well as in children. Renal impairment is clinically manifested with microscopic to macroscopic hematuria, mild proteinuria, sometimes even nephrotic; at other times with nephritic syndrome, which can be accompanied by various degrees of renal insufficiency ${ }^{33}$. Renal impairment can precede skin manifestations of the disease. Histologically, nephritis connected with HenochSchonlein purpura is characterized as IgA nephropathy with relatively wide morphological manifestation from focal mesangial proliferative glomerulonephritis to necrotizing form with crescent formation ${ }^{34}$. Mesangial IgA deposits are characteristic feature (Fig. 6, 7).

\section{Cryoglobulinemic vasculitis}

Cryoglobulins are immunoglobulins that precipitate reversibly in the cold, typically at $4{ }^{\circ} \mathrm{C}$, sometimes even higher temperature. Type I cryoglobulin occurs in monoclonal gammopathies and comprises monoclonal immunoglobulin without antibody activity; types II and III are characterized by the presence of mixed cryoglobulins, composed at least of two types of immunoglobulins. Type II comprises monoclonal immunoglobulins with rheumatoid factor activity against polyclonal IgG, type III includes polyclonal components $^{35}$. Mixed cryoglobulinemia of type III is associated with systemic connective tissue diseases, leukemia, hepato-biliary diseases or infections. Close relationship between mixed cryoglobulinemia of type II and virus of hepatitis $\mathrm{C}$ has repeatedly been proven. Mixed cryoglobulinemia is characterized by skin purpura with the presence of leukocytoklastic vasculitis. Skin lesions may be accompanied by extensive ulcerations or mutilations. Weakness, fever, arthralgia and Raynaud's syndrome also occur. Peripheral neuropathy accompanied with dysesthesia or anesthesia is also characteristic. Simultaneous hepatosplenomegalia is frequently the result of hepatitis $\mathrm{C}$ infection ${ }^{36}$. Symptoms of kidney impairment include proteinuria and microscopic hematuria often accompanied with symptoms of mild renal insufficiency. Nephritic syndrome, hypertension or nephrotic syndrome can also clinically occur. Progression to severe form of renal insufficiency occurs more frequently in men patients and older patients. The presence of mixed cryoglobulin can be proved in the laboratory; significant complement consumption is another characteristic finding as well as rheumatoid factors positivity. Renal biopsy, most frequently in type II mixed cryoglobulinemia, proves membranoproliferative glomerulonephritis with relatively intense infiltration consisting of neutrophils and monocytes, "double contour" of basement membrane, and during episodes of acute nephritic syndrome - also the presence of amorphous, eosinophilic, PAS positive intraluminal deposits ${ }^{37}$.

\section{Takayasu's arteritis}

Rarely this can be associated with glomerulonephritis; usually mild mesangial proliferation, exceptionally also membranoproliferative or crescentic glomerulonephritis ${ }^{38}$. Some cases of secondary AA amyloidosis have also been reported. Renal artery stenosis is a relatively frequent complication $^{39}$.

\section{HYPERURICEMIA AND KIDNEYS}

Fifty years ago, gout was one of the most frequent reasons for renal insufficiency in middle-aged men. The reason for the decline in its prevalence is significant decrease in incidence of chronic tophaceous gout due to the progress in diagnostics and treatment as well as elimination of latent lead intoxication from water pipes. Gout can manifest as a chronic interstitial nephritis with the presence of monosodium urate crystals in the renal parenchyma or even the presence of kidney tophi. It usually emerges in long-term untreated hyperuricemia and clinically it is often associated with hypertension and various degrees of chronic renal failure ${ }^{40}$. Hyperuricemic nephropathy, caused by a large amount of uric acid filtered into primary urine, is associated with acute form of renal impairment. Concentration of the urine volume associated with worsened solubility of urates leads to their precipitation in renal tubules, their blockade, to tubular necrosis, inflammation and acute renal failure. Kidneys are enlarged; in ultrasound examination they are shown as bright. This syndrome can be encountered also during chemotherapy of lymphomas, less frequently solid tumors, and even spontaneously in myeloproliferative diseases ${ }^{41}$. Another noticeable association is the formation of uric acid stones, which occur in connection with urate crys- 
talluria, mainly in overproducers and hyperexcretors of uric acid. Theithiasis in hyperuricemia is also composed of other types minerals such as calcium salts ox oxalates. Uric acid stones are more often found in hereditary hyperuricemic syndromes (Lesch-Nyhan syndrome, HPRT deficiency, PRPS hyperactivity, glycogenosis type I/glycogen storage disease type I) $\left(\right.$ ref. $\left.^{42}\right)$.

\section{AL AND AA AMYLOIDOSIS}

The disease is caused by deposition of insoluble protein - amyloid - in various tissues. Primary systemic amyloidosis (AL) occurs mostly in association with multiple myeloma - approximately in 5\% of the patients with this disease. Amyloid is composed mainly of immunoglobulin light chains which are overproduced in multiple myeloma and which are not sufficiently removed. Various manifestations of amyloidosis may be present: nephropathies with nephrotic syndrome, peripheral sensorimotor polyneuropathy, carpal tunnel syndrome, macroglossia, cardiomyopathy, hepatosplenomegaly, subcutaneous nodules and periorbital purpura. Primary amyloidosis can also be accompanied by joint manifestations. Arthritis is often symmetric and relatively unpainful. Typically, it affects wrist joint, shoulder joint, sacroiliac joints or the knee joint. Shoulder arthropathies with diffuse thickening due to deposited amyloid are characteristic for the disease - known as "pad sign". Synovial fluid effusion is non-inflammatory and sediment may contain "amyloid bodies" containing amyloid deposits. AL amyloidosis is diagnostically confirmed by histological examination of bone marrow, the presence of a M-protein or light chains in immunoelectrophoresis of urine or serum, histological examination and typing of amyloid in renal biopsy, subcutaneous fat biopsy, biopsy of rectal tissue or tissue of affected parenchymatose organs or synovium ${ }^{43}$. Secondary (AA) amyloidosis can occur in autoimmune or systemic inflammatory diseases as rheumatoid arthritis, ankylosing spondylitis, Sjögren's syndrome, familial Mediterranean fever, Crohn disease, ulcerative colitis, tuberculosis, osteomyelitis, bronchiectasia and some neoplasms (e.g. Hodgkin disease). AA amyloidosis is characterized by extracellular tissue deposition of fibrils that are composed of fragments of serum amyloid A (SAA) protein, a major acute-phase reactant protein, produced predominantly by hepatocytes. The most typical clinical manifestation is weakness, peripheral edema and weight loss. The renal manifestation is present in the majority of patients and is characterized by proteinuria, nephritic syndrome and renal failure. The other typical sites of involvement are liver, splenic or GIT tract depositions. The cardiac manifestation is far less common than in the course of AL amyloidosis ${ }^{44}$.

\section{DRUG-INDUCED RENAL IMPAIRMENT}

Many drugs that are commonly used in rheumatology can lead to various types of kidney impairment and damage. The drugs associated with a higher risk of kidney damage are non-steroidal antirheumatic drugs and analgesics, gold salts, cyclosporine A, tacrolymus, D-pennicilamin. The kidney damage is not common in sulfasalazine, methotrexate, azathioprine, leflunomide, mycophenolate mofetil, antiuratics or biological drugs. Use of cyclophosphomide is associated with increased risk of onset of hemorrhagic cystitis, higher in intravenous pulse administration of this drug. The problematic of drug induced impairment of kidney is complicated and deserves separate review ${ }^{45}$.

\section{CONCLUSION}

This review represents typical examples of rheumatic diseases associated with a broad spectrum of clinical kidney damage and brings together information which is otherwise scattered in the literature. The authors hope the paper will become a source of information for rheumatologists, nephrologists and clinical pathologists interested in the diagnosis of patients with theses types of disease.

\section{AKNOWLEDGEMENT}

Supported by grant IGA Ministry of Health, CR, No. NT/13707-4 and by the internal grant of Palacký University Olomouc No. LF_2012_016.

\section{CONFLICT OF INTEREST STATEMENT}

Author's conflict of interest disclosure: None declared.

\section{REFERENCES}

1. Adu D, Emery P, Madaio M. Rheumatology and the kidney. 2nd ed. New York: Oxford University Press; 2012.

2. Lukáč J. Systémové choroby spojivového tkaniva. 1st ed. Bratislava: Osveta; 2010.

3. Wallace DJ. The clinical presentation of SLE. In: Wallace DJ, Hahn $\mathrm{BH}$, editors. In Dubois'lupus erythematosus. Philadelphia: Lea and Febiger; 1993.

4. Weening JJ, D'Agati WD, Schwartz MM, Seshan SV, Alpers CE, Appel $G B$, et al. Classification of glomerulonephritis in systemic lupus erythematosus revisited. J Am Soc Nephrol 2004;15:241-50.

5. Joseph RE, Radhakrishnan J, Appel GB. Antiphospholipid antibody syndrome and renal disease. Curr Opin Nephrol Hypertens 2001;10:175-81.

6. Leaker B, Fairley KF, Dowling J, Kincaid-Smith P. Lupus nephritis: Clinical and pathological correlation. Q J Med 1987;62:163-79.

7. Hebert LA, Dillon JJ, Middendorf DF, Lewis EJ, Peter JB. Relationship between appearance of urinary red blood cell/white blood cell casts and the onset of renal relapse in systemic lupus erythematosus. Am J Kidney Dis 1995;26:432-8.

8. Pogorevici A, Gluhovschi C, Gluhovschi G, Velciov SM, Trandafirescu V, Secrii RV. Hypertension in lupus nephritis. Rom J Intern Med 2006;44:295-316.

9. Penn H, Howie AJ, Kingdon EJ. Scleroderma renal crisis: patient characteristics and long-term outcomes. QJM 2007;100:485-94.

10. Batal I, Domsic RT, Medsger TA Jr, Bastacky S. Scleroderma Renal Crisis: A Pathology Perspective. Int J Rheumatol 2010;2010:543704. doi: $10.1155 / 2010 / 543704$ 
11. Steen VD, Medsger TA Jr. Long-term outcomes of scleroderma renal crisis. Ann Intern Med 2000;133:600-3.

12. O'Callaghan CA. Renal manifestations of systemic autoimmune disease: diagnosis and therapy. Best Pract Res Clin Rheumatol 2004;18:411-27.

13. Varga J, Fenves A. Scleroderma renal crisis, www.uptodate.com, last update $22 \mathrm{Feb} 2012$.

14. Maldonado ME, Perez M, Pignac-Kobinger J, Marx ET, Tozman EM, Freidinger EL, Hoffman RW. Clinical and immunologic manifestations of mixed connective tissue disease in a Miami population compared to a Midwestern US Caucasian population. J Rheumatol 2008;35:429-37.

15. Yen TH, Lai PC, Chen CC, Hsueh S, Huang JY. Renal involvement in patients with polymyositis and dermatomyositis.Int J Clin Pract 2005;59:188-93.

16. Maripuri S, Grande JP, Osborn TG, Fervenza FC, Matteson EL, Donadio $J V$, Hogan MC. Renal involvement in primary Sjogren's syndrome: A clinicopathologic study. Clin J Am Soc Nephrol 2009;4:1423-31.

17. Bossini N, Savoldi S, Franceschini Fl. Clinical and morphological features of kidney involvement in primary Sjögren's syndrome. Nephrol Dial Transplant 2001;16:2328-36.

18. imms RW, Prout MN, Cohen AS. The epidemiology of AL and AA amyloidosis. Baillieres Clin Rheumatol 1994;8:627-34.

19. Karstila K, Korpela M, Sihvonen S, Mustonen J. Prognosis of clinica renal disease and incidence of new renal findings in patients with rheumatoid arthritis: follow-up of a population-based study. Clin Rheumatol 2007;26:2089-95.

20. Karie S, Gandjbakhch F, Janus N, Launay-Vacher V, Rozenberg S, Mai Ba CU, Bourgeois P, Deray G. Kidney disease in RA patients: prevalence and implication on RA-related drugs management: the MATRIX study. Rheumatology (Oxford). 2008 Mar;47(3):350-4. doi: 10.1093/rheumatology/kem370

21. Zadrazil J, Tichý T, Horák P, Nikorjaková I, Zíma P, Krejcí K, Střébl P. IgA nephropathy associated with psoriasis vulgaris: a contribution to the entity of 'psoriatic nephropathy'. J Nephrol 2006;19:382-6.

22. Kovacsovics-Bankowski M, Zufferey P, So AK, Gerster JC. Secondary amyloidosis: a severe complication of ankylosing spondylitis. Two case-reports. Joint Bone Spine 2000;67:129-33.

23. Singh, G, Kumari N, Aggarwal A, Krishnani N, Misra R. Prevalence of subclinical amyloidosis in ankylosing spondylitis. J Rheumatol 2007;34:371-4.

24. Watts RA, Scott DG. Recent developments in the classification and assessment of vasculitis. Best Pract Res Clin Rheumatol 2009;23:42939.

25. Stockigt JR, Topliss DJ, Hewett MJ. High-renin hypertension in necrotizing vasculitis. N Engl J Med 1979;300:1218-23.

26. Gayraud M, Guillevin L, le Toumelin P, Cohen P, Lhote F, Casassus $P$ Jarrousse B. Long-term followup of polyarteritis nodosa, microscopic polyangiitis, and Churg-Strauss syndrome: analysis of four prospective trials including 278 patients. Arthritis Rheum 2001;44:666-75.

27. Guillevin L. Polyarteritis nodosa: Clinical charactetstics, outcome and treatment. In Adu D, Emery P, Madaio M. editors Rheumatology and the kidney. 1nd ed. New York: Oxford University Press;2001,p.228-45.

28. Westman KW, Bygren PG, Olsson H, Ranstam J, Wieslander J.. Relapse rate, renal survival, and cancer morbidity in patients with Wegener's granulomatosis or microscopic polyangiitis with renal involvement. J Am Soc Nephrol 1998;9:842-52.

29. Falk RJ, Hogan S, Carey TS, Jennette JC. Clinical course of anti-neutrophil cytoplasmic autoantibody-associated glomerulonephritis and systemic vasculitis. The Glomerular Disease Collaborative Network. Ann Intern Med 1990;113:656-63.

30. Falk RJ, Gross WL, Guillevin L, Hoffman GS, Jayne DR, Jennette JC, Kallenberg CG, Luqmani R, Mahr AD, Matteson EL, Merkel PA, Specks U, Watts RA Granulomatosis with polyangiitis (Wegener's): an alternative name for Wegener's granulomatosis. Arthritis Rheum 2011;63:863-4.

31. Sinico RA, Di Toma L, Maggiore U, Tosoni C, Bottero P, Sabadini E, Giammarresi G, Tumiati B, Gregorini G, Pesci A, Monti S, Balestrieri G, Garini G, Vecchio F, Buzio C. Renal involvement in Churg-Strauss syndrome. Am J Kidney Dis 2006;47:770-9.

32. Gibelin A, Maldini C, Mahr A. Epidemiology and etiology of wegener granulomatosis, microscopic polyangiitis, Churg-Strauss syndrome and Goodpasture syndrome: vasculitides with frequent lung involvement. Semin Respir Crit Care Med 2011;32:264-73.

33. Chang WL, Yang YH, Wang LC, Lin YT, Chiang BL.Renal manifestations in Henoch-Schönlein purpura: a 10-year clinical study. Pediatr Nephrol 2005;20:1269-72.

34. Habib R, Niaudet $P$, Levy M. Schönlein-Henoch purpura nephritis and IgA nephropathy. In: Renal Pathology with Clinical and Functional Correlations, Tisher CC, Brenner BM (Eds), Lippincott, Philadelphia 1993. p.472-85.

35. D'Amico G, Colasanti G, Ferrario F, Sinico RA. Renal involvement in essential mixed cryoglobulinemia. Kidney Int 1989;35:1004-14.

36. Sumida K, Ubara Y, Hoshino J, Suwabe T, Nakanishi S, Hiramatsu R, Takaichi K, Oohashi K. Hepatitis C virus-related kidney disease: various histological patterns. Clin Nephrol 2010;74:446-56.

37. Sinico RA, Winearls CG, Sabadini E, Fornasieri A, Castiglione A, D'Amico G. Identification of glomerular immune deposits in cryoglobulinemia glomerulonephritis. Kidney Int 1988;34:109-16.

38. Jha V, Chung KS. Takayasu's arteritis. In: In Adu D, Emery P, Madaio M. editors Rheumatology and the kidney. 1 nd ed. New York: Oxford University Press; 2001, p.258-72.

39. Chugh KS, Sakhuja V. Takayasu's arteritis as a cause of renovascular hypertension in Asian countries. Am J Nephrol 1992;12:1-8.

40. Cameron JS, Simmonds HA. Uric acid, gout and the kidney. J Clin Pathol 1981;34:1245-54.

41. Jones DP, Mahmoud H, Chesney RW. Tumor lysis syndrome: pathogenesis and management. Pediatr Nephrol 1985;9:206-12.

42. Jurecka A. Inborn errors of purine and pyrimidine metabolism. J Inherit Metab Dis. 2009;32:247-63.

43. Adam Z, Ščudla V. Clinical manifestations of AL-amyloidosis and some other types of amyloidosis [Klinické manifestace AL amaloidózy a některých dalších typu amyloidózy]. Vnitr Lek 2001;47:36-45.

44. Lachmann HL, Goodman HJB, Gilbertson JA, Gallimore JR, Sabin CA, Gillmore JD, Hawkins PN. Natural history and outcome in systemic AA amyloidosis. N Engl J Med 2007;356:2361-71.

45. Horák P, Tichý T, Zadražil J. Renal manifestations of rheumatic diseases and kidney damage caused by drugs commonly used in rheumatology [Ledvinné manifestace revmatických chorob a postižení ledvin léčivy často užívanými v revmatologii]. In: Pavelka K, Vencovský J, Horák P, Šenolt L, Mann H, Štěpán J (ed) Revmatologie, Maxdorf;2012, p.129-37. 